\title{
Solvent-Dictated Sodium Sulfur Redox Reactions: Investigation of Carbonate and Ether Electrolytes
}

\author{
Huang Zhang ${ }^{1,2,3} \mathbb{D}^{\text {, Thomas Diemant }}{ }^{4}{ }^{-}$, Bingsheng Qin ${ }^{2,3}$, Huihua $\mathrm{Li}^{2,3}$, R. Jürgen Behm ${ }^{2,4}$ \\ and Stefano Passerini $2,3, *$ D \\ 1 Xi'an Institute of Flexible Electronics (IFE), Northwestern Polytechnical University (NPU), \\ 127 West Youyi Road, Xi'an 710072, Shaanxi, China; iamhzhang@nwpu.edu.cn \\ 2 Helmholtz Institute Ulm, Helmholtzstraße 11, 89081 Ulm, Germany; bingsheng.qin@kit.edu (B.Q.); \\ huihua.li@kit.edu (H.L.); juergen.behm@uni-ulm.de (R.J.B.) \\ 3 Karlsruhe Institute of Technology (KIT), D-76021 Karlsruhe, Germany \\ 4 Institute of Surface Chemistry and Catalysis, Ulm University, Albert-Einstein-Allee 47, D-89081 Ulm, \\ Germany; thomas.diemant@uni-ulm.de \\ * Correspondence: stefano.passerini@kit.edu; Tel.: +49-731-503-4101
}

Received: 9 January 2020; Accepted: 12 February 2020; Published: 14 February 2020

\begin{abstract}
Sulfur-based cathode chemistries are essential for the development of high energy density alkali-ion batteries. Here, we elucidate the redox kinetics of sulfur confined on carbon nanotubes, comparing its performance in ether-based and carbonate-based electrolytes at room temperature. The solvent is found to play a key role for the electrochemical reactivity of the sulfur cathode in sodium-sulfur $(\mathrm{Na}-\mathrm{S})$ batteries. Ether-based electrolytes contribute to a more complete reduction of sulfur and enable a higher electrochemical reversibility. On the other hand, an irreversible solution-phase reaction is observed in carbonate solvents. This study clearly reveals the solvent-dependent $\mathrm{Na}-\mathrm{S}$ reaction pathways in room temperature $\mathrm{Na}-\mathrm{S}$ batteries and provides an insight into realizing their high energy potential, via electrolyte formulation design.
\end{abstract}

Keywords: sodium-sulfur; redox kinetics; carbonate; ether; electrolyte

\section{Introduction}

The identification of efficient and effective but low-cost energy storage technologies is still a challenge, preventing the full integration of renewable energy sources into the grid at present. Rechargeable batteries represent one of the best promises for such a target, at least for a number of applications. Here, electrical energy can be efficiently stored and released according to demand, and their compact size makes them highly suitable for use at small grid-scale. Among the most promising electrode materials for such applications is certainly sulfur, which can potentially enable lithium metal anode batteries with about five times higher specific energy compared to current lithium-ion batteries, while being rather inexpensive [1]. Nonetheless, there is still concern with the foreseen resource and supply risks of lithium [2].

Therefore, sodium-sulfur (Na-S) batteries appear to be an ideal candidate due to the rather low economic and geopolitical impact of their raw materials $[3,4]$. The theoretical capacity of a $\mathrm{Na}-\mathrm{S}$ battery is $\sim 1672 \mathrm{mAh} \mathrm{g}^{-1}$, based on the sulfur with final product of $\mathrm{Na}_{2} \mathrm{~S}$. Despite the success of high-temperature $\mathrm{Na}-\mathrm{S}$ batteries $\left(>300^{\circ} \mathrm{C}\right)$ for grid-scale application, the problems associated with the solid electrolyte and/or cell sealing integrity failures, resulting in the risk of molten sodium explosive reactions, motivate the exploration for alternatives. A decrease in operation temperature could, in fact, offer the opportunity to improve the durability and safety of the Na-S battery [5]. Thus, the development of room temperature (RT) Na-S batteries with conventional, organic solvent-based 
electrolytes is triggering tremendous research interest [6]. In fact, considering their expected low cost, RT Na-S batteries may be the solution for the future of stationary and large-scale energy storage, enabling efficient and effective use of sustainable energy sources [6,7]. So far, most of the work has focused on the exploration of polymer electrolytes, either gel-polymer or solid-polymer, to suppress the polysulfides' shuttle pathway [8-12]. Moreover, attempts to fabricate sodium polysulfides' electrodes with carbonaceous interlayers and functional separators have been demonstrated to enhance the cycling stability of Na-S batteries [13-15]. However, RT Na-S batteries are still suffering from low reversible capacity and poor cycling stability. The low reversible capacity is mainly ascribed to the low electric conductivity of bulk sulfur and the sluggish reaction kinetics between sulfur and sodium, resulting in the poor utilization of the sulfur cathode [9]. In addition, the high self-discharge rate and rapid capacity fading due to sodium polysulfides' formation and shuttling across the electrolyte appear almost inevitable for RT Na-S batteries. Recently, intensive efforts have been made to identify and prepare highly efficient S-host substrates from functional carbons and inorganic metal oxides (sulfide), improving the utilization of the sulfur active material [16-23].

Although the understanding of the sulfur reduction reactions in conventional organic electrolytes is a precondition for the realization of high performance RT Na-S batteries, only very few studies have directly been devoted to unfold the sulfur conversion reaction and intermediates under battery conditions, in these carbon frameworks. A few studies have demonstrated the pronounced effects of the organic electrolytes' solvation properties on the lithium-sulfur ( $\mathrm{Li}-\mathrm{S})$ redox reactions [24-27]. Thus, understanding the solvent-dependent $\mathrm{Na}-\mathrm{S}$ redox processes, i.e., how the solvent affects the $\mathrm{Na}-\mathrm{S}$ redox reactions, may provide significant insight, allowing the design of improved electrolytes for high performance $\mathrm{Na}-\mathrm{S}$ batteries.

In this work, we systematically investigate the electrolyte solvent on the sulfur redox reaction pathway in RT Na-S batteries, comparing its performance in ether- and carbonate-based electrolytes. The use of tetraethyleneglycol-dimethyl-ether (TEGDME) ether-based electrolyte contributes to a more complete reduction of sulfur and enables a higher electrochemical reversibility. On the other hand, an irreversible solution phase reaction is observed in carbonate solvents. Both in situ X-ray diffraction (XRD) and ex situ X-ray photoelectron spectroscopy (XPS) measurements were performed to reveal the sulfur redox reaction process. This study presents a basic understanding on the solvent-dependent sulfur redox reactions, providing a solid basis for the systematic development of room temperature $\mathrm{Na}-\mathrm{S}$ batteries.

\section{Results and Discussion}

In order to address the major problem originating from the insulating nature of sulfur, the sulfur/carbon nanotube (S/CNT) composite was synthesized by a simple melt-diffusion method, which is briefly described in the Experimental section [28]. Results on the characterization of the as-prepared S/CNT composite are presented in Figure S1 (see Supporting Information). The scanning electron microscopy (SEM) images, revealing the morphology of the S/CNT composite, show no obvious aggregation of the sulfur particles, which indicates a homogenous distribution of the active sulfur in the carbon host. The XRD pattern confirms the orthorhombic crystal structure of cyclo- $\mathrm{S}_{8}$ (PDF\#74-1465). The broad diffraction peak located at $25^{\circ}$ can be attributed to the graphitic CNT. The TG curve shows a single-stage sulfur loss, by evaporation between 200 and $300{ }^{\circ} \mathrm{C}$. Quantitative evaluation yields a sulfur content of about $69 \mathrm{wt} . \%$. Initially, the S/CNT electrode was investigated in the Li-S battery to confirm its activity. As shown in Figure S2 (panels $a$ and $b$ ), the composite shows a specific discharge capacity of $1020 \mathrm{mAh} \mathrm{g}^{-1}$ (based on sulfur) at $100 \mathrm{~mA} \mathrm{~g}^{-1}$ and maintained $490 \mathrm{mAh} \mathrm{g}^{-1}$ at $1675 \mathrm{~mA} \mathrm{~g}^{-1}$, without any capacity fading over 75 cycles.

The solvent-dependent redox kinetics and the reaction behavior of the RT Na-S cells were further investigated in two different electrolytes, namely, $1.5 \mathrm{M} \mathrm{NaClO}_{4}$ in TEGDME with $0.2 \mathrm{M} \mathrm{NaNO}_{3}$ and $1.0 \mathrm{M} \mathrm{NaClO}_{4}$ in propylene carbonate/ethylene carbonate (PC/EC, 1:1 v/v) with $5 \mathrm{wt} . \%$ fluoroethylene carbonate (FEC), which are commonly used for Na-S batteries. The CV scans of S/CNT electrodes in these electrolytes are shown in Figure 1. The test of the cell employing the TEGDME-based electrolyte 
(panel a) shows three cathodic peaks at 2.2, 1.6, and 1.0 V, supporting for a three-step reduction of sulfur in the presence of $\mathrm{Na}$ ions. Two broad anodic peaks centered at 2.0 and $2.4 \mathrm{~V}$ indicate, however, that the oxidation occurs in two steps. In contrast, for the cell employing the PC/EC-based electrolyte, we only find a single clear reduction peak at $2.1 \mathrm{~V}$ (panel $b$ ), followed by two other features barely distinguishable at lower potentials. No peaks are detected during the anodic scan. Such a complete irreversibility may result from a rapid nucleophilic attack of reduced sulfur species on the carbonate solvents, as it was reported for the analogous lithium system [24]. The first galvanostatic charge/discharge profiles of the S/CNT electrode at $50 \mathrm{~mA} \mathrm{~g}^{-1}$ are presented in Figures 2a and S3 (see Supporting Information). Three distinct voltage plateaus are observed at 2.3, 1.7, and $1.1 \mathrm{~V}$ during the discharge of the TEGDME-based cell, which is consistent with the CV results. The electrode shows an initial specific discharge capacity of $828 \mathrm{mAh} \mathrm{g}^{-1}$ and a specific charge capacity of $774 \mathrm{mAh} \mathrm{g}^{-1}$, resulting in an initial Coulombic efficiency of $93.5 \%$. The high coulombic efficiency is attributed to the presence of $\mathrm{NaNO}_{3}$, which is proposed to reduce/suppress self-discharge. However, at higher specific currents (e.g., $500 \mathrm{~mA} \mathrm{~g}^{-1}$ ), both the Coulombic efficiency and the reversible capacity are rather poor (c.f., Figure S4). Compared with the Li-S chemistry (c.f., Figure S2a,b), the Na-S cells exhibit a different voltage (kinetics) and long-term cycling behavior. In fact, a rapid capacity fade occurs, which may be due to the dissolution of sodium polysulfides and their migration through the electrolyte (see Figure $2 b$ ). Using the PC/EC-based electrolyte, the S/CNT electrode shows a lower specific discharge capacity (i.e., $420 \mathrm{mAh} \mathrm{g}^{-1}$, corresponding to an average reduction state of $\mathrm{S}_{4}{ }^{2-}$ ) and negligible charge capacity (see Figure S3 in Supporting Information). Such an extremely poor reversibility makes the carbonate-based electrolyte unsuitable for $\mathrm{Na} / \mathrm{S}$ batteries, at least under these conditions.
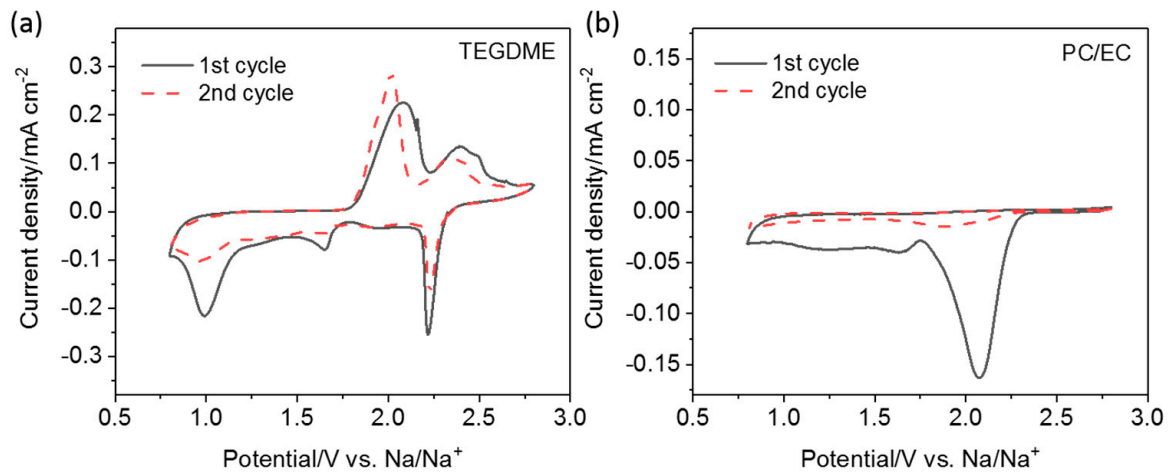

Figure 1. Slow scan cyclic voltammograms $(\mathrm{CVs})\left(0.1 \mathrm{mV} \mathrm{s}^{-1}\right)$ of room temperature (RT) sodium-sulfur (Na-S) cells using tetraethyleneglycol-dimethyl-ether (TEGDME) (a) and propylene carbonate/ethylene carbonate (PC/EC) (b) based electrolytes.
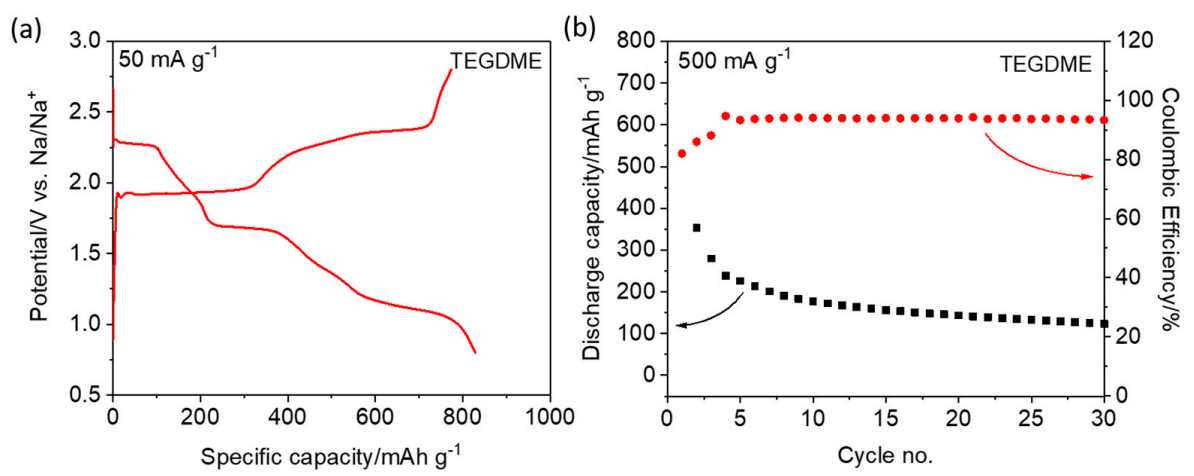

Figure 2. First charge/discharge cycle voltage profiles (a) and cycling performance (b) of sulfur/carbon nanotube (S/CNT) electrodes in Na-S cells using a TEGDME-based electrolyte. 
Electrochemical impedance spectroscopy (EIS) was applied on the assembled cells after resting $(3 \mathrm{~h})$ at the open circuit voltage (OCV) to obtain information on the self-discharge behavior. The impedance spectra exhibit two distorted semicircles in the high and medium frequency regions, followed by a steep increase in the low frequency regions. These represent the resistance of the passivation layer, the charge transfer resistance and the solid-state diffusion, respectively [29]. The intercept with the $\mathrm{x}$ axis at high frequency is attributed to the electrolyte resistance. The passivation layer resistance is associated with the unstable solid-electrolyte interphase (SEI), caused by the shuttle effect in the cathode and sodium dendrites on the anode. Nyquist plots recorded using the ether and carbonate electrolytes, respectively, are presented in Figure 3. As seen in Figure 3a, the cell using a TEGDME electrolyte has a higher film resistance than that employing carbonate. This results from the dissolution of polysulfides and the side reaction of the sodium metal electrode with the electrolyte, leading to a thicker passivation layer in the ether-based electrolyte than in the carbonate electrolyte [30,31]. The cell employing the TEGDMA electrolyte shows much higher electrolyte and SEI resistances, resulting from polysulfide dissolution. This indicates a clear role of dissolved sodium polysulfides in the formation of the passivation layer. Overall, the TEGDME-based Na-S cell shows a much smaller charge transfer resistance than the carbonate-based cell, indicating faster redox kinetics in the former case.
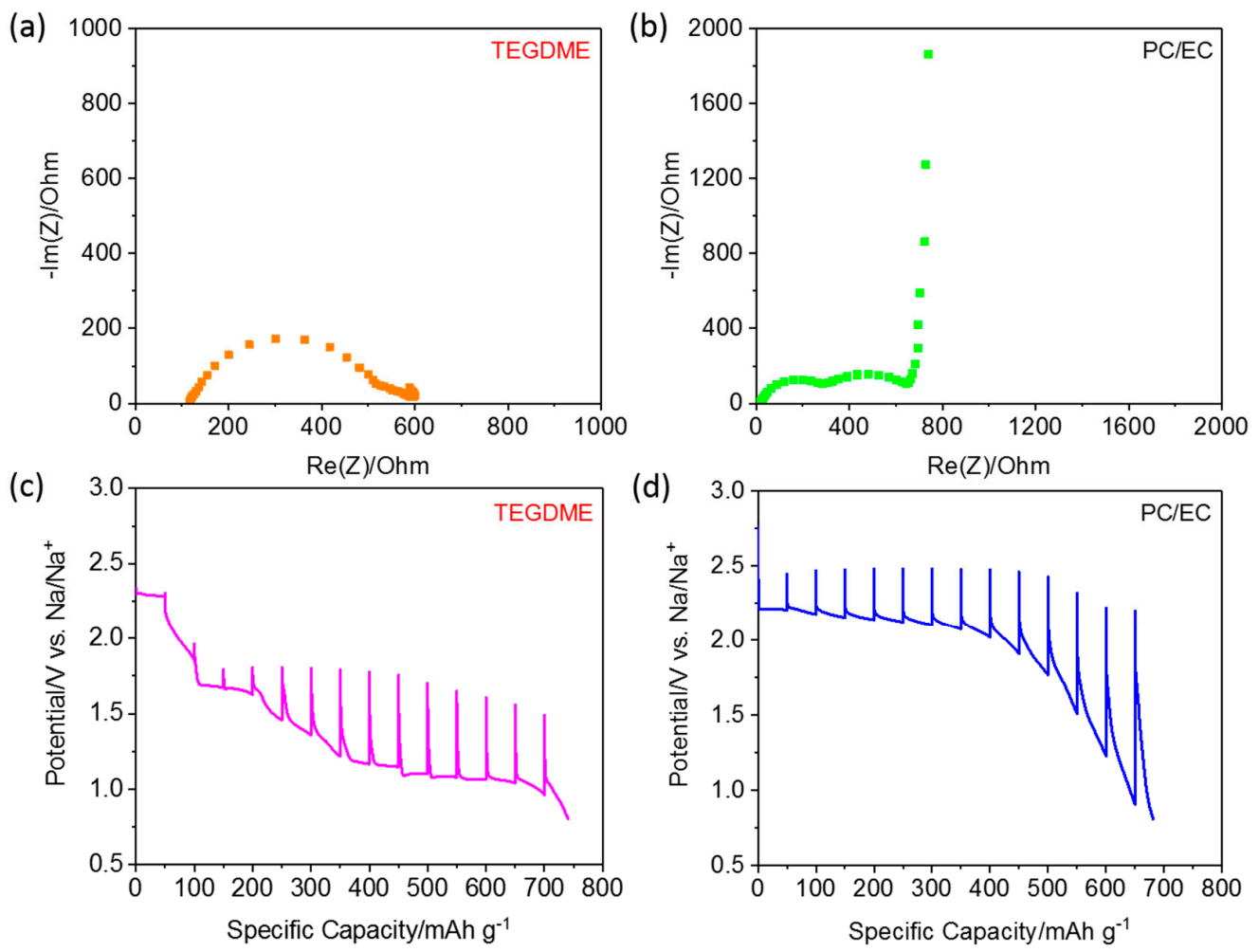

Figure 3. Nyquist plots at the end of open circuit voltage (OCV) rest and galvanostatic intermittent titration techniques (GITT) profiles of the Na-S cells in TEGDME $(\mathbf{a}, \mathbf{c})$ and PC/EC $(\mathbf{b}, \mathbf{d})$ electrolytes.

The sodiation overpotentials and kinetics of the S/CNT electrodes in the two electrolytes were evaluated by galvanostatic intermittent titration techniques (GITT), using specific current pulses of $50 \mathrm{~mA} \mathrm{~g}^{-1}$ per one hour, each followed by a rest period of $6 \mathrm{~h}$. The resulting voltage profiles are shown in Figure 3c,d [27]. The overall voltage profiles of the two cells during sodiation resemble those obtained during the galvanostatic discharge (c.f., Figures 2a and S3). The overpotential of the S/CNT electrode in the PC/EC-based electrolyte increases sharply with the state of discharge (SoD), reflecting the decreasing kinetics. In contrast, the electrode tested in the TEGDME-based electrolyte shows a moderate overpotential at the beginning of the sodiation, indicating that the electrode kinetics for 
the conversion of $S_{8}$ to long-chain polysulfides are rather fast. However, an increased polarization can be observed in the low voltage range. This phenomenon can be explained by the slow reaction kinetics for the conversion of the long-chain polysulfides into short-chain polysulfides, which is generally considered as a two-phase liquid-solid reaction. At the end, we find a small decrease on the overpotential, possibly due to the slight decrease of mass transport resistance at the end of the conversion reaction [32]. The different overpotentials for the sodiation process, which are mainly caused by the activation overpotentials, clearly indicate different activation energies for the RT Na-S reaction in carbonate and in ether-based electrolytes. It should be noted that the discharge capacity in the GITT measurement is higher than that obtained during continuous galvanostatic discharge, indicating that the milder GITT conditions (low pulse current and long rest periods) promote the utilization of sulfur and/or polysulfides in the carbon host, which has also been noted in $\mathrm{Li}-\mathrm{O}_{2}$ batteries [33].

To understand the intermediates and products of the S/CNT cathode at different sodiation states, we performed an in situ X-ray diffraction (XRD) analysis [34]. The XRD patterns of a S/CNT electrode in TEGDME collected during the first discharge-charge cycle are shown in the contour map ( $2 \theta$ range of $10-42^{\circ}$ ) in Figure 4 . To illustrate the phase changes more clearly, XRD diffractograms obtained at selected stages of sodiation $(1.8 \mathrm{~V}, 1.4 \mathrm{~V}$ and $0.8 \mathrm{~V})$ and desodiation $(2.1 \mathrm{~V}$ and $2.8 \mathrm{~V})$ are presented in Figure 5 additionally. The diffractograms recorded in the course of the first discharge can be subdivided into three regions, which are consistent with the charge-discharge curves (c.f., Figure 4, left panel). The first region starts at the beginning of sodiation and ends with the first plateaus region in the charge-discharge curve at $\sim 1.7 \mathrm{~V}$. At the end of this region (see also diffractogram at $1.8 \mathrm{~V}$ in Figure $5 \mathrm{~b}$ ), the features of $S_{8}$ have disappeared completely. Instead, a broad peak located at $21.5^{\circ}$ appears, which can be attributed to the presence of soluble long-chain polysulfides. Hence, all elemental sulfur is transformed to soluble long-chain polysulfides in this region. Further reduction of the polysulfides occurs in the second region, and at the end of it, the (101), (102), (004) and (110) signals of crystalline $\mathrm{Na}_{2} \mathrm{~S}_{2}$ (PDF\#89-2753) appear in the diffractogram recorded at $1.4 \mathrm{~V}$ (c.f., Figure 5c). In the final region, the reduction of polysulfides to $\mathrm{Na}_{2} \mathrm{~S}_{2}$ proceeds, until the features of crystalline $\mathrm{Na}_{2} \mathrm{~S}_{2}$ reach the highest intensity at the end of the discharge process at $0.8 \mathrm{~V}$ (c.f., Figure $5 \mathrm{~d}$ ). Upon charging, the intensity of the features related to crystalline $\mathrm{Na}_{2} \mathrm{~S}_{2}$ decrease again, indicating the gradual re-oxidation to polysulfides. After recharging to $2.1 \mathrm{~V}$ (c.f., Figure 5e), the peaks of $\mathrm{Na}_{2} \mathrm{~S}_{2}$ are weakened, but are still detectable. Close to the end of the charging process (at $2.8 \mathrm{~V}$ in Figure $5 \mathrm{f}$ ), the $\mathrm{Na}_{2} \mathrm{~S}_{2}$ peaks disappear, while new diffraction peaks appear at $22.8^{\circ}$ and $28.5^{\circ}$, which correspond to the (101) and (300) features of cyclo- $\mathrm{S}_{6}$ (PDF\#86-2249). They possibly indicate a direct oxidation from $\mathrm{S}_{6}{ }^{2-}$ to elemental $\mathrm{S}_{6}$.

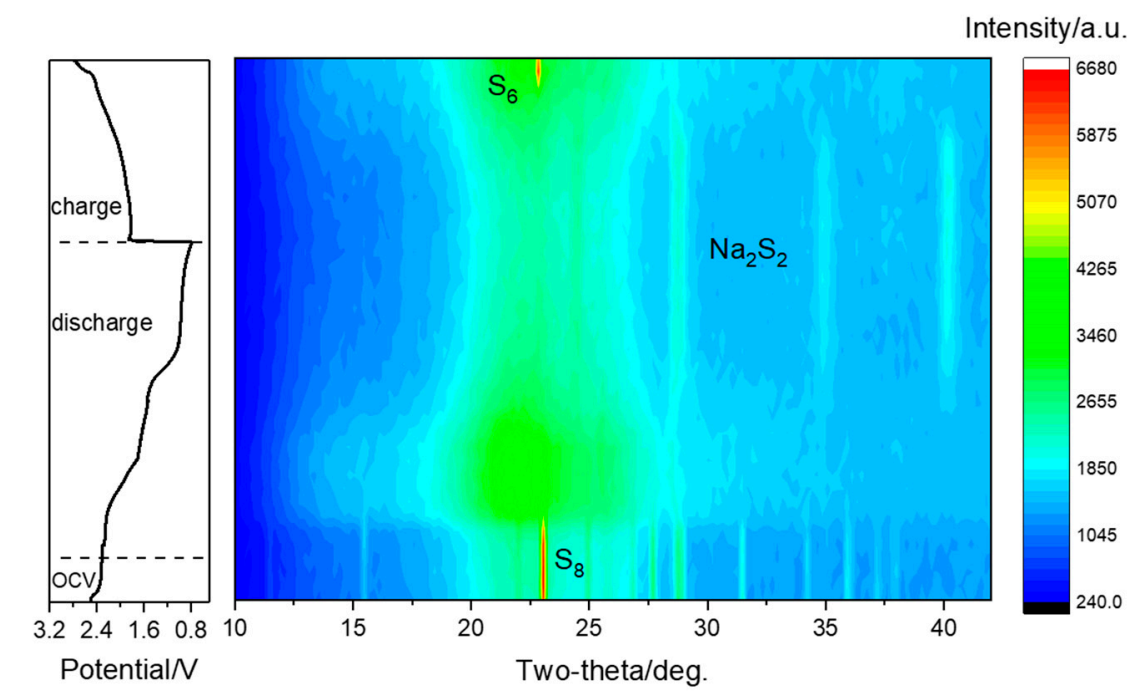

Figure 4. Contour map of in situ X-ray diffraction (XRD) results collected during the first charge-discharge cycle of S/CNT electrodes in TEGDME electrolyte. 

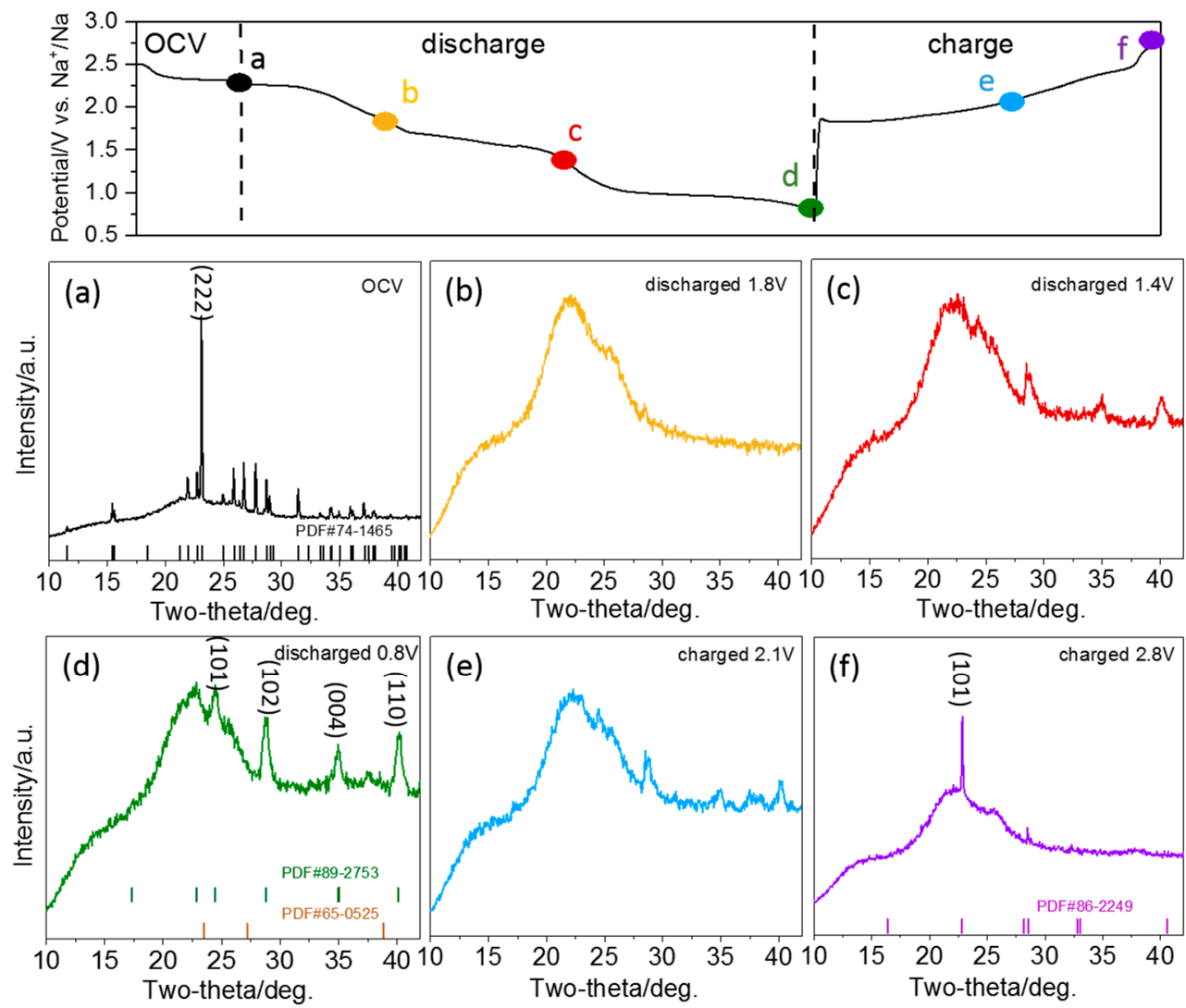

Figure 5. Selected in situ XRD patterns recorded at different stages of sodiation/desodiation at OCV (a) and potentials of $1.8(\mathbf{b}), 1.4(\mathbf{c})$, and $0.8 \mathrm{~V}(\mathbf{d})$ during discharge and $2.1(\mathbf{e})$ and $2.8 \mathrm{~V}(\mathbf{f})$ during charge of S/CNT electrodes in TEGDME electrolyte, respectively.

To reveal the changes of the chemical state of sulfur in the S/CNT electrode upon discharge and charge in TEGDME, ex situ XPS analysis was performed on the cycled electrodes at various discharge and charge states. Representative spectra in the $S 2 p$ range are shown in Figure 6 . The spectrum of the pristine electrode exhibits a spin-orbit doublet centered at 164.0 and $165.2 \mathrm{eV}$, which is in good agreement with the binding energy reported for the $S 2 p_{1 / 2}$ and $2 p_{3 / 2}$ peaks of $S_{8}$ molecules [35]. It may be noted that peaks at higher binding energy (beyond $166 \mathrm{eV}$ ) are observed in this and all following spectra originating from oxidized species. The next XPS measurement was performed on an electrode sodiated to the end of the first discharge plateau at $1.8 \mathrm{~V}$ (c.f., charge-discharge curve in Figure 6). Here the main peak doublet is detected at $163.7 / 164.9 \mathrm{eV}$, i.e., $0.3 \mathrm{eV}$ lower than in the first spectrum. It most probably contains contributions from bridging $S$ atoms $\left(\mathrm{S}_{B}{ }^{0}\right)$ in polysulfide species $\left(\mathrm{S}_{\mathrm{x}}{ }^{2-}\right)$ and from elemental sulfur. Additionally, another peak doublet with lower intensity appears at a lower binding energy $(161.6 / 162.8 \mathrm{eV})$, which we assign to the terminal $\mathrm{S}$ atoms $\left(\mathrm{S}_{\mathrm{T}}{ }^{-1}\right)$ of polysulfides. The intensity ratio of the two features is 4:1 in this measurement, showing just a minor excess of the expected value of $S_{B}$ to $S_{T}$ atoms in the initially formed long-chain polysulfide $S_{8}{ }^{2-}$ (of 3:1). Hence, assuming again the stepwise reaction from $\mathrm{S}_{8}$ to $\mathrm{S}_{8}{ }^{2-}$ and then to smaller polysulfides $\left(\mathrm{S}_{6}{ }^{2-}\right.$ etc.), this result suggests that most of the sulfur was transformed to $\mathrm{S}_{8}{ }^{2-}$ species at this point. The following XPS spectrum was recorded at the end of the second discharge plateau at $1.4 \mathrm{~V}$ (c.f., Figure $6 \mathrm{c}$ ). It exhibits two peaks' doublets at 163.3/164.5 and at 161.6/162.8 eV. The further peak shift of the first feature to lower binding energy indicates that the transformation of elemental sulfur to polysulfides is completed at this point. This is also corroborated by the intensity ratio of the two features, which shows a predominance of the peak doublet due to the terminal $\mathrm{S}$ atoms $\left(\mathrm{S}_{\mathrm{T}}{ }^{-1}\right)$ of polysulfides (by 0.3:1), i.e., small polysulfide species like $\mathrm{S}_{2}{ }^{2-}$ and $\mathrm{S}_{4}{ }^{2-}$ are present at this point. Considering that solid crystalline $\mathrm{Na}_{2} \mathrm{~S}_{4}$ has 
not been detected in XRD measurements at this stage of sodiation, it is plausible to assume that the formation of $\mathrm{Na}_{2} \mathrm{~S}_{4}$ takes place as a liquid to liquid reaction step in the TEGDME-based electrolyte. The XPS spectrum recorded after discharging to $1.4 \mathrm{~V}$ shows another small feature at even lower binding energy $(159.5 / 160.7 \mathrm{eV})$, which can be assigned to $\mathrm{S}^{2-}$. It is interesting to note that the in situ XRD measurements do not show the presence of the solid product $\mathrm{Na}_{2} \mathrm{~S}$ (PDF\#65-0525) at any stage of electrochemical sodiation. At the end of discharge (at $0.8 \mathrm{~V}$, c.f., Figure $6 \mathrm{~d}$ ), the S2p spectrum is dominated by the peak doublet related to terminal $S$ atoms $\left(S_{\mathrm{T}}{ }^{-1}\right)$, while the feature of bridging $S$ atoms $\left(S_{B}{ }^{0}\right)$ has almost disappeared. Furthermore, the peak doublet of $S^{2-}$ is detected again with small intensity. From this result we conclude that the main product upon complete discharge is $\mathrm{Na}_{2} \mathrm{~S}_{2}$, with a theoretical specific capacity of $836 \mathrm{mAh} \mathrm{g}^{-1}$, which agrees with previous studies of the $\mathrm{Na}-\mathrm{S}$ chemistry [36,37]. Upon recharging, the signal of bridging $S$ atoms $\left(\mathrm{S}_{\mathrm{B}}{ }^{0}\right)$ reappears (after charging to $2.1 \mathrm{~V}$ ) and eventually dominates the spectrum again (after charging to $2.8 \mathrm{~V}$ ). At the same time, its peak position shifts back to higher binding energy (to 163.8/165.0 eV after charging to $2.8 \mathrm{~V}$ ), indicating that elemental $S$ also contributes to this feature at the end of recharge. Surprisingly, the peak doublet due to $\mathrm{Na}_{2} \mathrm{~S}$ persisted in the spectra of the recharged samples, i.e., the reaction from $\mathrm{Na}_{2} \mathrm{~S}$ back to higher sulfides seems to be kinetically hindered, and it may be assumed that this reaction occurs only in microporous carbon with a small pore size [18].
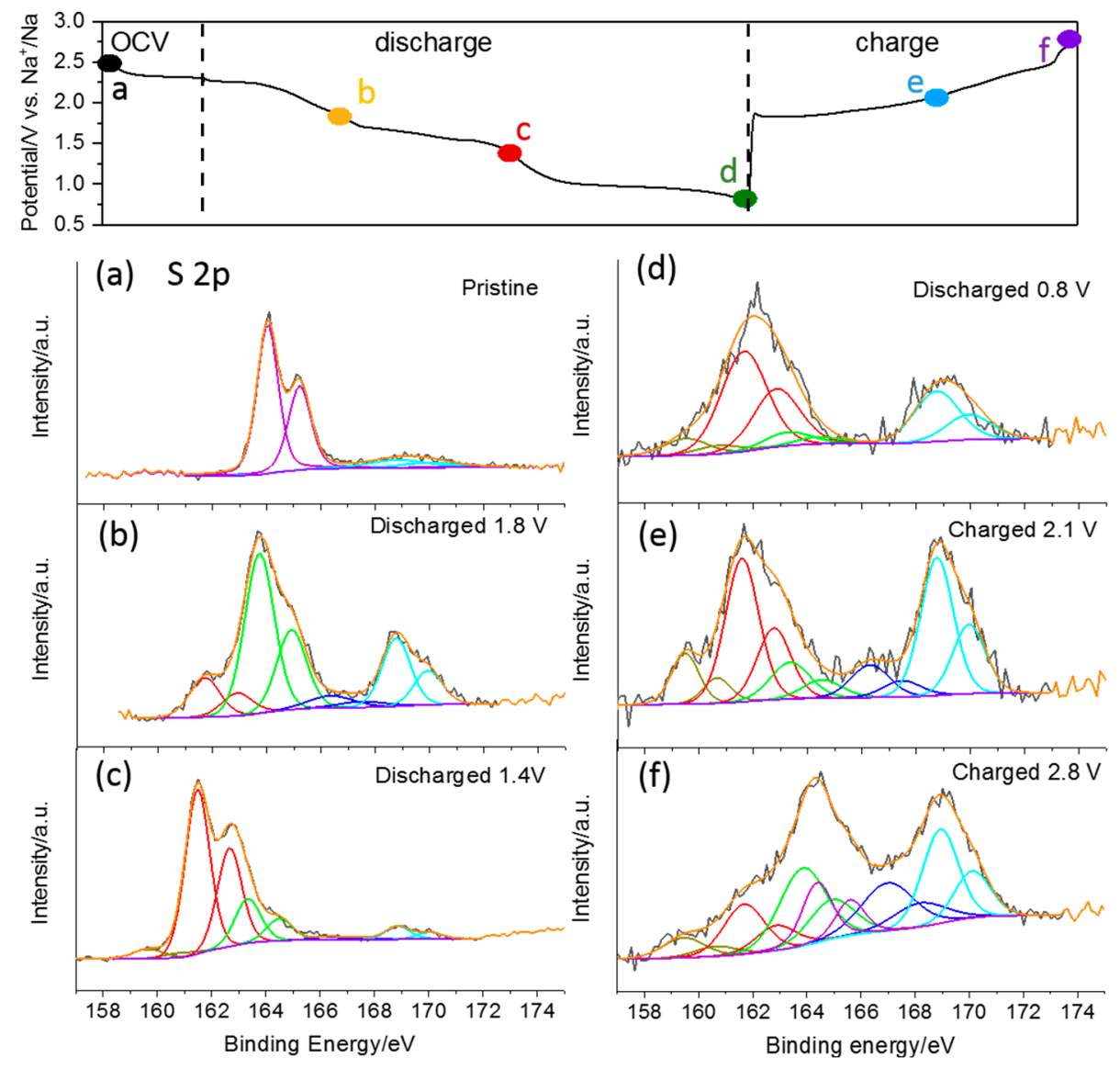

Figure 6. Ex situ XPS detail spectra in the S 2p range of S/CNT electrodes in TEGDME electrolyte at different stages of sodiation in the pristine state $(\mathbf{a})$, at $1.8(\mathbf{b}), 1.4(\mathbf{c})$ and $0.8 \mathrm{~V}(\mathbf{d})$ and desodiation at 2.1 (e) and $2.8 \mathrm{~V}(\mathbf{f})$.

To probe the reaction mechanism of sodiation of the S/CNT electrodes in the carbonate (PC/EC) based electrolyte, we collected similar in situ XRD diffractograms and ex situ XPS spectra. Since charging of the electrode does not work in this carbonate electrolyte, these experiments were performed 
only after discharge to various voltages. The in situ XRD patterns during the 1st discharge are shown in a contour map of the $2 \theta$ range of $10-42^{\circ}$ in Figure S5 (see Supporting Information). Initially, the intensity of the main sulfur reflection peaks gradually decreases, while the peak located at $22^{\circ}$ broadens during further discharge. Selected in situ XRD patterns recorded during discharge are shown in Figure S6a. As expected, the 1st XRD pattern measured at a discharged state of $2.2 \mathrm{~V}$ can be related to the pure S/CNT composite (c.f., Figure S1). An obvious peak at $\sim 31^{\circ} 2 \theta$ can be attributed to the (101) reflection of sodium metal (PDF\#89-4082). With increasing sodiation, all XRD features disappear except for the characteristic peak of sodium metal, i.e., the electrode materials become completely amorphous. No additional crystalline peaks can be detected in the diffractogram recorded at the end of the discharge process (at $0.8 \mathrm{~V}$ ), suggesting that there is no crystalline product in carbonate electrolyte upon sodiation. A high-resolution XPS detailed spectrum of the S2p region of a S/CNT electrode after discharge to $0.8 \mathrm{~V}$ is shown in Figure S6b. Three S2p peak doublets are detected. The dominating doublet at $163.8 / 165.0 \mathrm{eV}$ can be assigned to the bridging $S$ atoms $\left(\mathrm{S}_{\mathrm{B}}{ }^{0}\right)$ in polysulfide species $\left(\mathrm{S}_{\mathrm{x}}{ }^{2-}\right)$ or to elemental sulfur, the smaller one at lower binding energy to the terminal $\mathrm{S}$ atoms $\left(\mathrm{S}_{\mathrm{T}}{ }^{-1}\right)$ of polysulfides $(161.6 / 162.8 \mathrm{eV})$, and the last one to oxidized sulfur species $(168.8 / 170.0 \mathrm{eV})$, respectively. For $\mathrm{S}_{8}{ }^{2-}$, the first product which is expected upon sodiation of $S_{8}$, a ratio of $S_{B}$ to $S_{T}$ atoms of 3:1 is expected. Experimentally, the peak intensity ratio of the doublets at $163.8 / 165.0 \mathrm{eV}$ and $161.6 / 162.8$ is approximately 8:1. Thus, according to the XPS measurement, there should still be a sizable amount of elemental sulfur present on the surface of the sodiated S/CNT electrode, together with higher-order polysulfides, most probably $\mathrm{S}_{8}{ }^{2-}$. This can be explained by a dissolution of sulfur into the electrolyte, which occurs before the initial sodiation reaction. The results of the characterization indicate that the cyclo- $\mathrm{S}_{8}$ is only reduced to $\mathrm{Na}_{2} \mathrm{~S}_{8}$ upon sodiation, while the next reaction steps are inhibited. From the $\mathrm{Li}-\mathrm{S}$ system, it is well-known that long-chain polysulfides like $\mathrm{S}_{8}{ }^{2-}$ are dissolved in the carbonate solvent and then react with each other [24].

\section{Materials and Methods}

\subsection{Materials Synthesis}

Sulfur power (S, >99.995\%) and graphitic carbon nanotubes (CNT, multi-walled, 50-90 nm diameter) were purchased from Sigma-Aldrich. The CNTs were pre-treated with concentrated $\mathrm{HNO}_{3}$ (65\%, Merck Millipore) at $80^{\circ} \mathrm{C}$ for $12 \mathrm{~h}$ before use. The S/CNT composite was prepared by a simple melt-diffusion method. Stoichiometric amounts of $S$ and CNT (75:25 by mass) were mixed thoroughly by grinding in a mortar. Then the mixture was sealed in a glass vial under argon and heated to $155^{\circ} \mathrm{C}$ for $12 \mathrm{~h}$. After cooling down to RT, the mixture was ground again and heated in a tube furnace under argon flow at $200^{\circ} \mathrm{C}$ for $30 \mathrm{~min}$ to remove the residual sulfur covering the CNT surface.

\subsection{Electrolyte Preparation}

Anhydrous sodium perchlorate $\left(\mathrm{NaClO}_{4}, \mathrm{ACS}>98 \%\right)$ and sodium nitrate $\left(\mathrm{NaNO}_{3},>99.995 \%\right)$ were purchased from Alfa-Aesar and Sigma-Aldrich, respectively. These salts were dried at $120^{\circ} \mathrm{C}$ under high vacuum $\left(<10^{-7} \mathrm{mbar}\right)$ for $24 \mathrm{~h}$ before use. Tetraethyleneglycol-dimethyl-ether (TEGDME, anhydrous, $>99.5 \%$ ) was purchased from Sigma-Aldrich. Propylene carbonate (PC), ethylene carbonate (EC) and fluoroethylene carbonate (FEC) were received from BASF (battery grade). All solvents were dried with molecular sieves ( $0.3 \mathrm{~nm}$, Millipore) for at least 2 weeks and stored in an argon-filled glove box, with $\mathrm{H}_{2} \mathrm{O}$ and $\mathrm{O}_{2}$ contents lower than $0.1 \mathrm{ppm}$. The electrolytes were prepared by dissolving the appropriate amount of sodium salts into the desired solvents (in glovebox), to obtain the following electrolytic solutions: $1.5 \mathrm{M} \mathrm{NaClO}_{4}$ in TEGDME with $0.2 \mathrm{M} \mathrm{NaNO}_{3}$ and $1.0 \mathrm{M} \mathrm{NaClO}_{4}$ in PC:EC with $5 \mathrm{wt}$ \% fluoroethylene carbonate (FEC). 


\subsection{Electrochemical Characterizations}

Electrochemical measurements were conducted using CR2032 coin cells. The S-based cathodes were fabricated by a doctor-blade coating of slurry on an Al foil, and the slurry was composed of $80 \mathrm{wt} . \%$ obtained S/CNT composites as active materials, $10 \mathrm{wt} . \%$ Super C65 conductive carbon (IMERYS) and $10 \mathrm{wt} . \%$ polyvinylidenefluoride as binder (PVdF, 6020 Solef, Solvay) in N-methyl-2-pyrrolidone (NMP, anhydrous, Sigma-Aldrich). After pre-drying at $60{ }^{\circ} \mathrm{C}$ in air, electrodes with a diameter of $12 \mathrm{~mm}$ were punched, pressed and finally dried at $40^{\circ} \mathrm{C}$ under vacuum $\left(<10^{-3}\right.$ mbar $)$ for $12 \mathrm{~h}$. The sulfur mass loading was about $1.0 \mathrm{mg} \mathrm{cm}^{-2}$. The cells were assembled using glass fiber discs (GF/D, Whatman) as separators and sodium metal foil as counter electrode in an argon-filled glove box $\left(\mathrm{H}_{2} \mathrm{O}\right.$ and $\mathrm{O}_{2}$ contents lower than $0.1 \mathrm{ppm}$ ). The amount of electrolyte in each cell was $40 \mu \mathrm{L}$. Galvanostatic charge-discharge tests were carried out using a battery tester (Maccor 4000 Battery system, USA) in the potential range of 0.8-2.8 V. Cyclic voltammetry (CV) and electrochemical impedance spectroscopy (EIS) tests were performed using a multichannel VMP3 potentiostat/galvanostat (Biologic Science Instruments, France). The impedance spectra were recorded in a frequency range of $10^{5}-10^{-2} \mathrm{~Hz}$ with a signal amplitude of $10 \mathrm{mV}$. For the galvanostatic intermittent titration technique (GITT) experiments, the electrodes were sodiated stepwise ( $50 \mathrm{~mA} \mathrm{~g}^{-1}$ for 1 hour) and then allowed to rest for 6 hours. The steps were repeated until the cell potential reached $0.8 \mathrm{~V}$. All the electrochemical measurements were performed in a climatic chamber set at $20 \pm 1^{\circ} \mathrm{C}$.

\subsection{Materials and Electrode Characterizations}

An X-ray diffraction (XRD) test was performed with the Bragg-Brentano geometry (D8 Advance diffractometer, Bruker, Germany). The powder diffraction pattern was recorded with $\mathrm{Cu} \mathrm{K}$ radiation $(\lambda=0.154 \mathrm{~nm})$ in a $2 \theta$ range of $10^{\circ}-90^{\circ}$ with a step size of $0.01^{\circ}$. The in situ XRD patterns of the $\mathrm{S} / \mathrm{CNT}$ electrode were recorded in the $2 \theta$ range of $10^{\circ}-42^{\circ}$, applying a specific current of $25 \mathrm{~mA} \mathrm{~g}^{-1}$. The morphological characterization was conducted by field emission scanning electron microscopy (1550VP FE-SEM, Carl Zeiss, Germany). The sulfur content was determined by thermogravimetric analysis (TGA-209F, Netzsch, Germany). Ex situ X-ray photoelectron spectroscopy (XPS) measurements were performed on cycled electrodes (PHI 5800 Multi Technique ESCA system, Physical Electronic, USA). The electrodes were first polarized at specific potentials in Swagelok-type cells. After 1 hour of potentiostatic rest, the electrodes were extracted from the cells and subjected to XPS measurements. The XPS spectra were recorded using monochromatized Al K $(1486.6 \mathrm{eV})$ radiation with a take-off angle of $45^{\circ}$ and pass energies at the electron analyzer of 29.35 and $93.9 \mathrm{eV}$. The $\mathrm{C} 1$ 's peak at $284.8 \mathrm{eV}$ was used for calibration.

\section{Conclusions}

In summary, our study revealed solvent-dependent $\mathrm{Na}-\mathrm{S}$ reaction pathways and highlighted the role of polysulfide solubility on the reversibility of $\mathrm{Na}-\mathrm{S}$ batteries. The solvent selection significantly affects the redox kinetics of RT Na-S batteries. With the TEGDME solvent, sulfur exhibited a faster self-discharge which we explain by the strong solvation and a more complete reduction of solution-phase sulfur species upon discharge. Hence, this is a superior choice under certain situations. In this electrolyte sulfur undergoes a series of sulfur intermediates of $\mathrm{S}_{8}{ }^{2-}, \mathrm{S}_{6}{ }^{2-}, \mathrm{S}_{4}{ }^{2-}$, and $\mathrm{S}_{2}{ }^{2-}$, where $\mathrm{S}_{2}{ }^{2-}$ is the main product with a theoretical specific capacity of $836 \mathrm{mAh} \mathrm{g}^{-1}$. However, the formation of redox active polysulfides results in a severe capacity loss and phase limitation. In carbonate solution, in contrast, the performance is mainly limited by the solution-phase reaction, indicating the strategy of confinement sulfur in microporous carbon with small pore sizes, with reversible solid-solid reaction for rechargeable $\mathrm{Na}-\mathrm{S}$ batteries, further indicating the controlled solubility of redox polysulfide species is also required. Of course, other factors such as the solvation structure, viscosity, donor number, as well as dielectric constant, may also influence the reaction rates of the $\mathrm{Na}-\mathrm{S}$ cells. Future work focusing on a systematic controlled variation of various solvent properties and the examination of how each 
parameter affects the sulfur reaction kinetics will provide further insights into the function and role of the solvent in RT Na-S batteries, providing a solid basis for systematic development. Moreover, design of efficient sulfur host materials should be another important point to improve the polysulfide stability in the efficiency of RT Na-S batteries.

Supplementary Materials: The following are available online at http://www.mdpi.com/1996-1073/13/4/836/s1, Figure S1: SEM images, XRD pattern and TGA curve of S/CNT composite, Figure S2: charge/discharge profile and cycling performance of S/CNT electrodes in Li-S batteries, Figure S3: charge/discharge profile of S/CNT electrode at $50 \mathrm{~mA} \mathrm{~g}^{-1}$ in a Na-S cell using PC/EC-based electrolyte, Figure S4: charge/discharge profile of a $\mathrm{S} / \mathrm{CNT}$ electrode in a Na-S battery cell using TEGDME electrolyte at $500 \mathrm{~mA} \mathrm{~g}^{-1}$, Figure S5: contour map of in situ XRD diffractograms collected during the first charge of an S/CNT electrode in PC/EC electrolyte, Figure S6: ex situ XRD and XPS characterizations of S/CNT electrodes at different sodiation stages in PC/EC-based electrolyte.

Author Contributions: H.Z. designed and performed the experiments; H.Z. wrote the original manuscript; T.D. conceived the XPS measurement; B.Q. and H.L. synthesized the materials and prepared the electrodes; R.J.B. contributed to the discussion and analysis on the XPS results; S.P. revised the paper and supervised the work. All authors have read and agreed to the published version of the manuscript.

Funding: This research received no external funding.

Acknowledgments: The authors would like to acknowledge the support from Initiative and Networking Fund of the Helmholtz Association within the Network of Excellence on post-Lithium batteries (ExNet-0035). H.L. and B.Q. gratefully acknowledge the financial support from Chinese Scholarship Council (no. 201508370097, no. 201808410352). H.Z. acknowledges the financial support from the Fundamental Research Funds for the Central Universities (31020190QD029). This work contributes to the research performed at CELEST (Center for Electrochemical Energy Storage Ulm-Karlsruhe).

Conflicts of Interest: The authors declare no conflict of interest.

\section{References}

1. Bruce, P.G.; Freunberger, S.A.; Hardwick, L.J.; Tarascon, J.M. Li-O2 and Li-S batteries with high energy storage. Nat. Mater. 2012, 11, 19-29. [CrossRef]

2. Dunn, B.; Kamath, H.; Tarascon, J.-M. Electrical energy storage for the grid: A battery of choices. Science 2011, 334, 928-935. [CrossRef] [PubMed]

3. Palomares, V.; Serras, P.; Villaluenga, I.; Hueso, K.B.; Carretero-Gonzalez, J.; Rojo, T. Na-ion batteries, recent advances and present challenges to become low cost energy storage systems. Energy Environ. Sci. 2012, 5, 5884-5901. [CrossRef]

4. Zhang, H.; Hasa, I.; Passerini, S. Beyond insertion for Na-ion batteries: Nanostructured alloying and conversion anode materials. Adv. Energy Mater. 2018, 8, 1702582. [CrossRef]

5. Lu, X.; Kirby, B.W.; Xu, W.; Li, G.; Kim, J.Y.; Lemmon, J.P.; Sprenkle, V.L.; Yang, Z. Advanced intermediate-temperature Na-S battery. Energy Environ. Sci. 2013, 6, 299-306. [CrossRef]

6. Wang, Y.-X.; Zhang, B.; Lai, W.; Xu, Y.; Chou, S.-L.; Liu, H.-K.; Dou, S.-X. Room-temperature sodium-sulfur batteries: A comprehensive review on research progress and cell chemistry. Adv. Energy Mater. 2017, 7, 1602829. [CrossRef]

7. Manthiram, A.; Yu, X. Ambient temperature sodium-sulfur batteries. Small 2015, 11, 2108-2114. [CrossRef]

8. Oshima, T.; Kajita, M.; Okuno, A. Development of sodium-sulfur batteries. Int. J. Appl. Ceram. Technol. 2004, 1, 269-276. [CrossRef]

9. Park, C.-W.; Ahn, J.-H.; Ryu, H.-S.; Kim, K.-W.; Ahn, H.-J. Room-temperature solid-state sodium/sulfur battery. Electrochem. Solid-State Lett. 2006, 9, A123-A125. [CrossRef]

10. Park, C.-W.; Ryu, H.-S.; Kim, K.-W.; Ahn, J.-H.; Lee, J.-Y.; Ahn, H.-J. Discharge properties of all-solid sodium-sulfur battery using poly (ethylene oxide) electrolyte. J. Power Sources 2007, 165, 450-454. [CrossRef]

11. Wang, J.; Yang, J.; Nuli, Y.; Holze, R. Room temperature Na/S batteries with sulfur composite cathode materials. Electrochem. Commun. 2007, 9, 31-34. [CrossRef]

12. Kim, J.-S.; Ahn, H.-J.; Kim, I.-P.; Kim, K.-W.; Ahn, J.-H.; Park, C.-W.; Ryu, H.-S. The short-term cycling properties of $\mathrm{Na} / \mathrm{PVdF} / \mathrm{S}$ battery at ambient temperature. J. Solid State Electrochem. 2008, 12, 861-865. [CrossRef] 
13. Yu, X.; Manthiram, A. Room-temperature sodium-sulfur batteries with liquid-phase sodium polysulfide catholytes and binder-free multiwall carbon nanotube fabric electrodes. J. Phys. Chem. C 2014, 118, 22952-22959. [CrossRef]

14. Yu, X.; Manthiram, A. Highly reversible room-temperature sulfur/long-chain sodium polysulfide batteries. J. Phys. Chem. Lett. 2014, 5, 1943-1947. [CrossRef]

15. Yu, X.; Manthiram, A. Ambient-temperature sodium-sulfur batteries with a sodiated Nafion membrane and a carbon nanofiber-activated carbon composite electrode. Adv. Energy Mater. 2015, 5, 1500350. [CrossRef]

16. Chen, Y.-M.; Liang, W.; Li, S.; Zou, F.; Bhaway, S.M.; Qiang, Z.; Gao, M.; Vogt, B.D.; Zhu, Y. A nitrogen doped carbonized metal-organic framework for high stability room temperature sodium-sulfur batteries. J. Mater. Chem. A 2016, 4, 12471-12478. [CrossRef]

17. Wang, Y.-X.; Yang, J.; Lai, W.; Chou, S.-L.; Gu, Q.-F.; Liu, H.K.; Zhao, D.; Dou, S.X. Achieving high-performance room-temperature sodium-sulfur batteries with S@interconnected mesoporous carbon hollow nanospheres. J. Am. Chem. Soc. 2016, 138, 16576-16579. [CrossRef]

18. Wei, S.; Xu, S.; Agrawral, A.; Choudhury, S.; Lu, Y.; Tu, Z.; Ma, L.; Archer, L.A. A stable room-temperature sodium-sulfur battery. Nat. Commun. 2016, 7, 11722. [CrossRef]

19. Carter, R.; Oakes, L.; Douglas, A.; Muralidharan, N.; Cohn, A.P.; Pint, C.L. A sugar-derived room-temperature sodium sulfur battery with long term cycling stability. Nano Lett. 2017, 17, 1863-1869. [CrossRef]

20. Lu, Q.; Wang, X.; Cao, J.; Chen, C.; Chen, K.; Zhao, Z.; Niu, Z.; Chen, J. Freestanding carbon fiber cloth/sulfur composites for flexible room-temperature sodium-sulfur batteries. Energy Storage Mater. 2017, 8, 77-84. [CrossRef]

21. Qiang, Z.; Chen, Y.-M.; Xia, Y.; Liang, W.; Zhu, Y.; Vogt, B.D. Ultra-long cycle life, low-cost room temperature sodium-sulfur batteries enabled by highly doped (N,S) nanoporous carbons. Nano Energy 2017, 32, 59-66. [CrossRef]

22. Ye, H.; Ma, L.; Zhou, Y.; Wang, L.; Han, N.; Zhao, F.; Deng, J.; Wu, T.; Li, Y.; Lu, J. Amorphous MoS3 as the sulfur-equivalent cathode material for room-temperature Li-S and Na-S batteries. Proc. Natl. Acad. Sci. USA 2017, 114, 13091-13096. [CrossRef] [PubMed]

23. Ma, D.; Li, Y.; Yang, J.; Mi, H.; Luo, S.; Deng, L.; Yan, C.; Rauf, M.; Zhang, P.; Sun, X.; et al. New strategy for polysulfide protection based on atomic layer deposition of $\mathrm{TiO} 2$ onto ferroelectric-encapsulated cathode: Toward ultrastable free-standing room temperature sodium-sulfur batteries. Adv. Funct. Mater. 2018, 28, 1705537. [CrossRef]

24. Gao, J.; Lowe, M.A.; Kiya, Y.; Abruña, H.D. Effects of liquid electrolytes on the charge-discharge performance of rechargeable lithium/sulfur batteries: Electrochemical and in-situ X-ray absorption spectroscopic studies. J. Phys. Chem. C 2011, 115, 25132-25137. [CrossRef]

25. Zou, Q.; Lu, Y.-C. Solvent-dictated lithium sulfur redox reactions: An operando UV-vis spectroscopic study. J. Phys. Chem. Lett. 2016, 7, 1518-1525. [CrossRef]

26. Fan, F.Y.; Pan, M.S.; Lau, K.C.; Assary, R.S.; Woodford, W.H.; Curtiss, L.A.; Carter, W.C.; Chiang, Y.-M. Solvent effects on polysulfide redox kinetics and ionic conductivity in lithium-sulfur batteries. J. Electrochem. Soc. 2016, 163, A3111-A3116. [CrossRef]

27. Fu, C.; Xu, L.; Aquino, F.W.; Cresce, A.v.; Gobet, M.; Greenbaum, S.G.; Xu, K.; Wong, B.M.; Guo, J. Correlating $\mathrm{Li}$--solvation structure and its electrochemical reaction kinetics with sulfur in subnano confinement. J. Phys. Chem. Lett. 2018, 9, 1739-1745. [CrossRef]

28. Pang, Q.; Liang, X.; Kwok, C.Y.; Nazar, L.F. Advances in lithium-sulfur batteries based on multifunctional cathodes and electrolytes. Nat. Energy 2016, 1, 16132. [CrossRef]

29. Xu, X.; Zhou, D.; Qin, X.; Lin, K.; Kang, F.; Li, B.; Shanmukaraj, D.; Rojo, T.; Armand, M.; Wang, G. A room-temperature sodium-sulfur battery with high capacity and stable cycling performance. Nat. Commun. 2018, 9, 3870. [CrossRef]

30. Kim, I.; Park, J.Y.; Kim, C.H.; Park, J.W.; Ahn, J.P.; Ahn, J.H.; Kim, K.W.; Ahn, H.J. A room temperature Na/S battery using a $\beta^{\prime \prime}$ alumina solid electrolyte separator, tetraethylene glycol dimethyl ether electrolyte, and a S/C composite cathode. J. Power Sources 2016, 301, 332-337. [CrossRef]

31. Kim, I.; Park, J.-Y.; Kim, C.; Park, J.-W.; Ahn, J.-P.; Ahn, J.-H.; Kim, K.-W.; Ahn, H.-J. Sodium polysulfides during charge/discharge of the room-temperature Na/S battery using TEGDME electrolyte. J. Electrochem. Soc. 2016, 163, A611-A616. [CrossRef] 
32. Park, J.-W.; Yamauchi, K.; Takashima, E.; Tachikawa, N.; Ueno, K.; Dokko, K.; Watanabe, M. Solvent effect of room temperature ionic liquids on electrochemical reactions in lithium-sulfur batteries. J. Phys. Chem. C 2013, 117, 4431-4440. [CrossRef]

33. Cui, Z.H.; Guo, X.X.; Li, H. Equilibrium voltage and overpotential variation of nonaqueous Li-O2 batteries using the galvanostatic intermittent titration technique. Energy Environ. Sci. 2015, 8, 182-187. [CrossRef]

34. Cañas, N.A.; Wolf, S.; Wagner, N.; Friedrich, K.A. In-situ X-ray diffraction studies of lithium-sulfur batteries. J. Power Sources 2013, 226, 313-319. [CrossRef]

35. Fantauzzi, M.; Elsener, B.; Atzei, D.; Rigoldi, A.; Rossi, A. Exploiting XPS for the identification of sulfides and polysulfides. Rsc Adv. 2015, 5, 75953-75963. [CrossRef]

36. Ryu, H.; Kim, T.; Kim, K.; Ahn, J.-H.; Nam, T.; Wang, G.; Ahn, H.-J. Discharge reaction mechanism of room-temperature sodium-sulfur battery with tetra ethylene glycol dimethyl ether liquid electrolyte. J. Power Sources 2011, 196, 5186-5190. [CrossRef]

37. Yang, F.; Mousavie, S.M.A.; Oh, T.K.; Yang, T.; Lu, Y.; Farley, C.; Bodnar, R.J.; Niu, L.; Qiao, R.; Li, Z. Sodium-sulfur flow battery for low-cost electrical storage. Adv. Energy Mater. 2018, 8, 1701991. [CrossRef]

(C) 2020 by the authors. Licensee MDPI, Basel, Switzerland. This article is an open access article distributed under the terms and conditions of the Creative Commons Attribution (CC BY) license (http://creativecommons.org/licenses/by/4.0/). 